\title{
Lung protective mechanical ventilation and two year survival in patients with acute lung injury: prospective cohort study
}

\author{
(a) (1) $\Theta$ OPEN ACCESS
}

\begin{abstract}
Dale M Needham associate professor ${ }^{12}$, Elizabeth Colantuoni assistant scientist ${ }^{3}$, Pedro A Mendez-Tellez assistant professor ${ }^{4}$, Victor D Dinglas research programme supervisor ${ }^{1}$, Jonathan E Sevransky assistant professor ${ }^{1}$, Cheryl R Dennison Himmelfarb associate professor ${ }^{6}$, Sanjay V Desai assistant professor ${ }^{1}$, Carl Shanholtz associate professor ${ }^{7}$, Roy G Brower professor ${ }^{1}$, Peter J Pronovost professor ${ }^{46}$
\end{abstract}

${ }^{1}$ Outcomes After Critical IIIness and Surgery Group, Division of Pulmonary and Critical Care Medicine, Johns Hopkins University School of Medicine, Baltimore, MD 21205, USA ; ${ }^{2}$ Department of Physical Medicine and Rehabilitation, Johns Hopkins University School of Medicine; ${ }^{3}$ Department of Biostatistics, Johns Hopkins University Bloomberg School of Public Health, Baltimore, MD, USA; ${ }^{4}$ Department of Anesthesiology and Critical Care Medicine, Johns Hopkins University School of Medicine; ${ }^{5}$ Department of Health Policy and Management, Johns Hopkins University Bloomberg School of Public Health, Baltimore, MD, USA; ${ }^{6}$ Johns Hopkins University School of Nursing, Baltimore, MD, USA; ${ }^{7}$ Division of Pulmonary and Critical Care Medicine, University of Maryland, Baltimore, MD, USA

\begin{abstract}
Objective To evaluate the association of volume limited and pressure limited (lung protective) mechanical ventilation with two year survival in patients with acute lung injury.

Design Prospective cohort study.

Setting 13 intensive care units at four hospitals in Baltimore, Maryland, USA.

Participants 485 consecutive mechanically ventilated patients with acute lung injury.

Main outcome measure Two year survival after onset of acute lung injury.

Results 485 patients contributed data for 6240 eligible ventilator settings, as measured twice daily (median of eight eligible ventilator settings per patient; $41 \%$ of which adhered to lung protective ventilation). Of these patients, 311 (64\%) died within two years. After adjusting for the total duration of ventilation and other relevant covariates, each additional ventilator setting adherent to lung protective ventilation was associated with a $3 \%$ decrease in the risk of mortality over two years (hazard ratio $0.97,95 \%$ confidence interval 0.95 to $0.99, P=0.002$ ). Compared with no adherence, the estimated absolute risk reduction in two year mortality for a prototypical patient with $50 \%$ adherence to lung protective ventilation was $4.0 \%(0.8 \%$ to $7.2 \%, P=0.012)$ and with $100 \%$ adherence was $7.8 \%$ (1.6\% to $14.0 \%, P=0.011)$.
\end{abstract}

Conclusions Lung protective mechanical ventilation was associated with a substantial long term survival benefit for patients with acute lung injury. Greater use of lung protective ventilation in routine clinical practice could reduce long term mortality in patients with acute lung injury.

Trial registration Clinicaltrials.gov NCT00300248.

\section{Introduction}

Survivors of severe critical illness, such as acute lung injury, and its more severe subset, acute respiratory distress syndrome (ARDS), commonly experience increased mortality and morbidity in the months and years after hospital discharge. ${ }^{1-3}$ Compared with age matched and sex matched controls, patients discharged from intensive care are two to five times more likely to die during three to 15 years' follow-up. ${ }^{3}$ Few interventions have been evaluated for improving this increased long term mortality. ${ }^{4}$

Randomised trials and meta-analyses have shown that use of volume limited and pressure limited mechanical ventilation (lung protective ventilation) in patients with acute lung injury substantially decreases short term mortality. ${ }^{5-9}$ A randomised trial of lung protective ventilation carried out by the ARDS Network ${ }^{8}$ found an $8.8 \%$ absolute reduction in short term mortality. This trial evaluated a ventilator tidal volume of 6 $\mathrm{mL} / \mathrm{kg}$ predicted body weight (calculated on the basis of a patient's sex and height ${ }^{8}$ ) and a plateau pressure (airway pressure measured after a 0.5 second end inspiratory pause) of $\leq 30 \mathrm{~cm}$ of water compared with a tidal volume of $12 \mathrm{~mL} / \mathrm{kg}$ predicted body weight and a plateau pressure of $\leq 50 \mathrm{~cm}$ of water. 
Understanding the effect of lung protective ventilation on long term survival is important, ${ }^{45}$ especially since critical care interventions with a mortality benefit at hospital discharge may not have a sustained benefit thereafter. ${ }^{10}$ Lung protective ventilation may have long term benefits owing to its reductions in inflammation, ventilator induced lung injury, and duration of non-pulmonary organ failure in the setting of the intensive care unit. $^{811}$

We evaluated the association of lung protective ventilation and average ventilator tidal volume with two year survival in patients with acute lung injury. We carried out this evaluation using a prospective cohort study design to understand the epidemiology and effects of lung protective ventilation as part of routine medical care and to avoid the ethical issues associated with randomly allocating patients to higher tidal volumes and pressures as part of a randomised trial.

\section{Methods}

From 2004-7 we enrolled into a prospective cohort study 520 consecutive mechanically ventilated patients with acute lung injury, diagnosed according to the American-European Consensus criteria (box). ${ }^{12}$ Patients were recruited from 13 medical, surgical, and trauma intensive care units at four academic teaching hospitals in Baltimore, Maryland, United States. Intensive care units that specialised in patients with neurological conditions, and patients with acute lung injury with primary neurological disease or head trauma were not eligible. We excluded patients who had pre-existing comorbid illness with a life expectancy of six or less months (for example, metastatic cancer), pre-existing cognitive impairment or communication/language barriers, no fixed address for follow-up, been transferred from another hospital and had pre-existing acute lung injury of more than 24 hours' duration, been mechanically ventilated for more than five days before onset of acute lung injury, previous lung resection, and a physician order for no escalation of care in the intensive care unit (for example, no vasopressors) at onset of acute lung injury. We obtained informed consent for prospective follow-up in writing after patients regained decision making capacity (or through proxies if patients remained incapable of decision making). ${ }^{13}$

\section{Assessment of primary outcome: mortality}

We prospectively evaluated patients at 3, 6, 12, and 24 months after onset of acute lung injury. Mortality status and date of death were obtained from family members and subsequently verified using a commercial version of the social security death master file ${ }^{14}$ or other publicly accessible records of death. Any patient for whom we could not determine mortality status was censored at the last day known to be alive.

\section{Assessment of primary exposure: lung protective mechanical ventilation}

After onset of acute lung injury, we recorded mechanical ventilator settings twice daily at 6 am and $6 \mathrm{pm}$ for the duration of the patient's ventilation at the study site hospital. A ventilator setting was defined as being "eligible" for lung protective ventilation if mechanical ventilation was delivered through an endotracheal or tracheostomy tube with a fraction of inspired oxygen $\left(\mathrm{FiO}_{2}\right) \geq 0.50$ or positive end expiratory pressure $>5 \mathrm{~cm}$ of water. We chose this definition of eligible because it approximated the threshold at which the ARDS Network ventilation protocol permitted trials of spontaneous breathing in which tidal volume and plateau pressure were not specified and controlled, and discontinuation of mechanical ventilation could be evaluated.

A ventilator setting was defined as "adherent" to lung protective ventilation if it was an eligible setting that met two criteria: tidal volume $\leq 6.5 \mathrm{~mL} / \mathrm{kg}$ predicted body weight (the threshold used in the ARDS Network tidal volume trial to designate study site adherence to the goal tidal volume of $6.0 \mathrm{~mL} / \mathrm{kg}$ predicted body weight) and a plateau pressure of $\leq 30 \mathrm{~cm}$ of water (based on documentation of respiratory therapy; in pressure regulated modes of ventilation, in which plateau pressure is not measured, we used peak pressure or the sum of positive end expiratory pressure and the prescribed increment in inspiratory pressure). We considered ventilator settings that used a mode of mechanical ventilation for which tidal volume is not routinely measured (that is, high frequency oscillation or airway pressure release modes) to be not eligible for assessing adherence to lung protective ventilation but we still included them in the statistical analysis using the cumulative number of each of these ventilator modes as time varying covariates. We excluded from analyses those patients without at least one eligible ventilator setting before death or discontinuation of mechanical ventilation because adherence to lung protective ventilation is undefined in this patient subset.

\section{Assessment of baseline and time varying covariates}

In this study we measured covariates potentially associated with ventilator settings or mortality, based on previous literature (for example,$\left.{ }^{15}\right)$ and a systematic process. ${ }^{16}$ We evaluated 10 baseline variables: age, sex, body mass index category, comorbidity (Charlson index ${ }^{17}$ ), severity of illness within 24 hours of admission to an intensive care unit (acute physiology and chronic health evaluation II score), ${ }^{18}$ primary risk factor for acute lung injury, type of intensive care unit (medical versus surgical), patient location before admission to intensive care (for example, emergency department), year of enrolment to study (first, second, or third), and study site identifier (1, 2, 3, or 4). Throughout the duration of ventilation we obtained time varying covariates from the medical record twice daily at 6 am and $6 \mathrm{pm}$, when recorded: positive end expiratory pressure, pressure of arterial oxygen $\left(\mathrm{PaO}_{2}\right), \mathrm{FiO}_{2}$, arterial $\mathrm{pH}$, and actual respiratory rate. From the data we calculated and included in the model a twice daily measure of static compliance of the respiratory system. ${ }^{19}$ Additional time varying covariates were measured once daily in the intensive care unit, including organ dysfunction (sequential organ failure assessment score ${ }^{20}$ ), sedation and delirium status (Richmond agitation and sedation scale ${ }^{21}$ and confusion assessment method for the intensive care unit $^{22}$ ), dose of systemic corticosteroids and neuromuscular blocking agents, and net fluid balance (total fluid input minus total fluid output).

\section{Statistical analysis}

We used descriptive statistics to summarise the data and compared these using Wilcoxon rank-sum and Fisher's exact tests, as appropriate. A Kaplan-Meier curve was used to describe the survival experience over the two years of follow-up.

A multivariable Cox proportional hazards regression model with time varying covariates was used to estimate the hazard ratios of mortality as a function of lung protective ventilation (the primary exposure variable) and all 27 covariates chosen a priori based on clinical relevance. The primary exposure was modelled as the time varying number of ventilator settings adherent to lung protective ventilation, with adjustment for the 


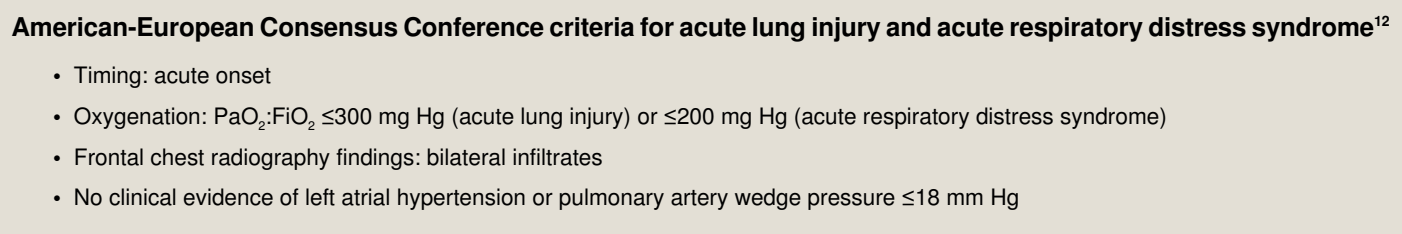

total duration of mechanical ventilation. When a similar magnitude of hazard ratios existed between categories we collapsed the categorical variables to binary variables. We examined Martingale residual plots to confirm appropriate modelling of continuous covariates, with no departures from linearity detected. Analysis of variance inflation factors confirmed the absence of any important multicollinearity in the full multivariable model. The Cox model allowed for separate baseline hazard functions for mortality during stay in the intensive care unit compared with after stay, as defined by a time varying indicator of discharge from the intensive care unit. We assessed the proportional hazard assumption for the full model using a trend test based on the Schoenfeld residual ${ }^{23}$ and graphical displays of the cumulative Schoenfeld residuals versus event times for each explanatory variable, indicating no important violation of this assumption. ${ }^{24}$

To illustrate the effect of lung protective ventilation on mortality, we used the multivariable Cox model to predict the survival function and cumulative risk of mortality at 1, 6, 12, 18, and 24 months after onset of acute lung injury for a prototypical patient who survived for at least four days of eligible mechanical ventilation and had median values for all continuous covariates and mode values for all binary covariates.

\section{Missing data}

For days in the intensive care unit during which a sedation or delirium assessment was not completed, we made a conservative assumption that coma (Richmond agitation and sedation scale score -4 or -5 ) and delirium were not present. For missing data on plateau pressure we used multiple imputation ${ }^{25}$ (with five datasets), as in previous research using ARDS Network data. ${ }^{26}$ As a secondary analysis, we repeated all analyses using a subset of the entire dataset excluding patients with complete missing ventilator data required for measuring the primary exposure to compare with results from the primary analysis using multiple imputation for missing data.

\section{Additional analyses}

We carried out additional a priori analyses. To determine if the findings were robust to the tidal volume and plateau pressure thresholds that defined an adherent ventilator setting, we reran the multivariable Cox model using different thresholds for adherence both for tidal volume ( $\leq 6.0$ to $\leq 9.0 \mathrm{~mL} / \mathrm{kg}$ predicted body weight) and for plateau pressure ( $\leq 25$ to $\leq 45 \mathrm{~cm}$ of water). In addition, we explored the association of mean tidal volume (analysed as a time varying variable over the duration of mechanical ventilation) with two year survival, modelling mean tidal volume as both a three level categorical exposure variable $(<6.5,6.5-8.5$, and $>8.5 \mathrm{~mL} / \mathrm{kg}$ predicted body weight $)$ and a continuous exposure variable. Using the same multivariable regression model, we also evaluated whether mean tidal volume, considered as a continuous exposure variable without accounting for plateau pressure, had a linear association with two year survival. In this evaluation, we calculated the estimated change in hazard of mortality across mean tidal volume between the multivariable Cox model assuming a linear relation with survival compared with assuming a flexible, non-linear relation achieved by adding a cubic spline (with three degrees of freedom) into the model.

We also carried out a post hoc propensity score analysis approach for non-binary treatments ${ }^{27}$ to compare with the primary analysis. Separate propensity scores were created using Poisson regression models for each of the number of eligible ventilator settings and the number of adherent ventilator settings using the previously described covariates for the multivariable regression models. Data were stratified into nine strata based on three levels of each propensity score, with a Cox model fit within each stratum with further adjustment for a subset of the relevant covariates. We calculated the overall propensity score adjusted hazard ratio and associated variance as a weighted average of the strata specific estimates.

We calculated that we would require a sample size of 520 patients to show a relative hazard of 0.70 for two year survival comparing two equally sized groups of patients (those receiving greater than compared with less than the median proportion of eligible ventilation days using lung protective ventilation) with an $\alpha$ of 0.05 and statistical power of more than $85 \%$. Statistical significance was defined as a two sided $\mathrm{P}<0.05$. All analyses were completed using R statistical software (version 2.11.1).

\section{Results}

Overall, 35 of 520 patients were excluded from analysis: 32 $(6 \%)$ had no eligible ventilator settings and three $(<1 \%)$ had missing data on height required for calculating predicted body weight and adherence to lung protective ventilation (fig $1 \Downarrow$ ). Thus data from 485 patients, with 6240 eligible ventilator settings and 12202 total ventilator settings, were available for analysis. For the secondary analysis of complete data, $30(6 \%)$ of the 485 eligible patients were excluded owing to missing ventilator variables required for measuring the primary exposure, leaving 455 patients with 4938 eligible ventilator settings and 10321 total ventilator settings.

Tables $1 \Downarrow$ and $2 \Downarrow$ present the patients' characteristics, ventilator variables, and other covariates related to the intensive care unit, by adherence to lung protective ventilation and by two year mortality status. Of 485 patients, $274(57 \%)$ were male and the median age (years) was 53 (interquartile range 42-63). Patients were predominantly admitted to a medical (compared with surgical) intensive care unit, with a median severity of illness (acute physiology and chronic health evaluation II) score of 27 (interquartile range 20-33, table 1). The median number of eligible ventilator settings per patient was 8 (interquartile range 3-15). The median duration (days) of mechanical ventilation was 9 (interquartile range 5-17), stay in the intensive care unit was 13 (8-22), and hospital stay was 21 (13-36).

Of 6240 eligible ventilator settings, 2548 (41\%) were adherent to lung protective ventilation, with no significant temporal trends in adherence observed over the three year study period. Of the 485 patients, $417(86 \%)$ received $50 \%$ or less and $68(14 \%)$ received more than $50 \%$ of their twice daily ventilator settings adherent to lung protective ventilation. A total of 180 (37\%) patients never received lung protective ventilation during any of their twice daily ventilator settings. Patients who were ever 
(versus never) exposed to lung protective ventilation were younger, and a significantly greater proportion were male and received neuromuscular blockers (table 1 ).

Overall, 311 (64\%) of the 485 patients died during the two years after onset of acute lung injury. Mortality status at two years was not available for $29(6.0 \%)$ of the 485 patients, and these patients were censored in the analysis. The mortality rate increased over time, particularly over the first year of follow-up, from $44 \%$ at 30 days to $52 \%$ at 90 days and $62 \%$ at one year (fig $2 \Downarrow$ ). Those who were alive after two years were significantly younger with lower comorbidity, severity of illness, and organ failure scores (table 1).

During the two year follow-up, survival was independently associated with several covariates: younger age; lower comorbidity, organ failure scores, cumulative fluid balance, and days with neuromuscular blockers; and a greater number of high frequency oscillation or airway pressure release ventilator settings (table $3 \Downarrow$ ). After adjusting for the total duration of mechanical ventilation and all other covariates, for each additional adherent ventilator setting measured twice daily, the risk of mortality over two years decreased by $3 \%$ (hazard ratio $0.97,95 \%$ confidence interval 0.95 to $0.99, \mathrm{P}=0.002$ ). For a prototypical patient, this finding equates to an estimated absolute risk reduction in two year mortality of $4.0 \%$ ( $95 \%$ confidence interval $0.8 \%$ to $7.2 \%, \mathrm{P}=0.012$ ) for $50 \%$ ventilator adherence and $7.8 \%$ (1.6\% to $14.0 \%, \mathrm{P}=0.011$ ) for $100 \%$ adherence compared with a $49.7 \%$ baseline mortality under the assumption of no adherence to lung protective ventilation (fig $3 \Downarrow$ ).

The results of the primary analysis of 485 patients were robust to varying both the tidal volume and the plateau pressure thresholds used to define adherence to lung protective ventilation. In addition, the primary results using multiple imputation for missing data were similar when replicated in the secondary analysis of 455 patients, which excluded those with complete missing data for the primary exposure, with a hazard ratio for each additional adherent ventilator setting of $0.96(95 \%$ confidence interval 0.94 to $0.99, \mathrm{P}=0.001$ ). Finally, results of the post hoc propensity score analyses were consistent with results from the primary analysis.

Compared with a mean tidal volume $<6.5 \mathrm{~mL} / \mathrm{kg}$ predicted body weight, the adjusted hazard ratios for two year mortality for a mean tidal volume of 6.5 to $8.5 \mathrm{~mL} / \mathrm{kg}$ predicted body weight was 1.59 (1.19 to $2.14, \mathrm{P}=0.001)$ and for $>8.5 \mathrm{~mL} / \mathrm{kg}$ predicted body weight was 1.97 (1.23 to 3.16, $\mathrm{P}=0.004$ ). Moreover, when tidal volume was modelled as a continuous variable, no evidence supported a non-linear relation between two year survival and mean tidal volume (fig $4 \Downarrow ; \mathrm{P}=0.182$ for the non-linear terms of a cubic spline model), with an adjusted hazard ratio of 1.18 (1.07 to $1.31, \mathrm{P}=0.001$ ), indicating an $18 \%$ relative increase in mortality for each $1 \mathrm{~mL} / \mathrm{kg}$ predicted body weight increase in average tidal volume.

\section{Discussion}

In this multisite, prospective cohort study of patients with acute lung injury, adherence to lung protective ventilation was associated with improved two year survival, with an absolute reduction in mortality of about $4 \%$ and $8 \%$ when $50 \%$ and $100 \%$ adherence, respectively, were compared with no adherence. These findings were robust to differing thresholds of tidal volume and plateau pressure used to define adherence to lung protective ventilation. Moreover, average tidal volume showed an independent linear relation with two year survival, with an $18 \%$ relative increase in the risk of mortality over two years for each $1 \mathrm{~mL} / \mathrm{kg}$ predicted body weight increase in average tidal volume over the duration of mechanical ventilation. Thus, within the setting of routine clinical practice, use of lung protective ventilation was strongly associated with a substantial, long term survival benefit for patients with acute lung injury.

\section{Comparison with other studies}

No existing studies of lung protective ventilation have been designed to evaluate long term survival in patients. ${ }^{6}$ The high two year mortality observed in this study is consistent with previous research showing increased long term mortality for patients after discharge from an intensive care unit versus age and sex matched population controls, and with the known risks for long term mortality, including high comorbidity, organ failure, and severity of illness, ${ }^{328}{ }^{29}$ which were observed in this patient sample.

This observational study allowed evaluation of lung protective ventilation within a setting of routine clinical practice in four teaching hospitals. Only $41 \%$ of all eligible ventilator settings were adherent to lung protective ventilation, and when twice daily collected ventilator settings were evaluated $37 \%$ of patients never received lung protective ventilation. These results represent an improvement from previous studies ${ }^{30-32}$ and from usual care practice before randomisation in the original ARDS Network trial in which mean baseline tidal volume was 10 $\mathrm{mL} / \mathrm{kg}$ predicted body weight. ${ }^{8}$ There are many known reasons for non-adherence to lung protective ventilation ${ }^{31}{ }^{33-35}$ and still substantial room for improvement with use of this life saving intervention. ${ }^{66}{ }^{37}$ Rigorous knowledge translation research, aimed at improving the implementation of clinical research into practice, is needed to maximise the public's return on investment from clinical and preclinical research that established the short term efficacy of lung protective ventilation. ${ }^{37}$ These knowledge translation efforts are especially important given the ageing population and the higher incidence and mortality associated with acute lung injury and mechanical ventilation with increasing age. . $^{8-40}$

In this study, the duration of neuromuscular blockade (but not cumulative dose) was associated with an increased risk of mortality over two years. These findings contrast with the 90 day survival benefit of early neuromuscular blockade in severe acute respiratory distress syndrome from a recent randomised trial. ${ }^{41}$ This difference in findings is possibly due, in part, to noticeably different use of these drugs in this study compared with the randomised trial protocol.

This study also found a two year survival benefit with use of high frequency oscillation and airway pressure release modes of ventilation in selected patients, with adjusted hazard ratios for each additional high frequency oscillation or airway pressure release ventilator setting (measured twice daily) of $0.93(95 \%$ confidence interval 0.88 to $0.97, \mathrm{P}=0.002)$ and 0.98 ( 0.96 to $0.99, \mathrm{P}=0.005$ ), respectively. However, the study was not specifically designed and analysed to evaluate these alternative modes of ventilation, which have not been compared with conventional lung protective ventilation in any large scale randomised trial. ${ }^{6}$ Hence the results for these alternative modes of ventilation must be interpreted with caution.

\section{Limitations of the study}

This study has potential limitations. Firstly, as this study was observational we cannot prove causation between lung protective ventilation and increased two year survival since both measured and unmeasured characteristics differed between patient groups receiving and not receiving lung protective ventilation. Given the decrease in short term mortality established in previous 
studies,$^{5-9}$ however, a randomised trial to evaluate the long term effects of lung protective ventilation would not be ethical. Causality is plausible given the known short term benefits of lung protective ventilation ${ }^{6-9}{ }^{11}$ and the dose-response effect of lung protective ventilation observed in this study. Secondly, the plateau pressure required for determining adherence to lung protective ventilation was not always recorded in the medical record, occurring in $21 \%$ of the eligible ventilator settings, with a median number of missing values across all 485 patients of 1 (interquartile range 0-3). This is not an uncommon finding in routine clinical practice, with plateau pressure, peak end expiratory pressure, or tidal volume missing in about $40 \%$ of patients in both a population based observational study ${ }^{42}$ and in the ARDS Network trial before randomisation of the groups. ${ }^{8}$ These missing data have the potential to bias results; however, both the primary analysis with imputation of missing data and a secondary complete case analysis showed similar results, which provide some reassurance. Greater efforts to routinely measure and record plateau pressure and tidal volume in $\mathrm{mL} / \mathrm{kg}$ predicted body weight, and to explicitly consider these ventilator variables during bedside rounds, may improve adherence to lung protective ventilation. ${ }^{33}$ Finally, only teaching hospitals were evaluated and exclusion criteria were applied in selecting eligible patients for this study; hence generalisability of the findings may be limited. However, four hospitals with 13 intensive care units participated, providing variation in the medical care provided to participants, and the number of exclusion criteria were limited (compared with randomised trials of lung protective ventilation) which aids in generalisability.

\section{Conclusion}

Lung protective mechanical ventilation is associated with a substantial survival benefit for patients with acute lung injury over two year's follow-up. Average tidal volume showed a linear relation with two year survival, such that even a relatively small decrease in average tidal volume over stay in the intensive care unit was independently associated with an important decrease in risk of mortality. Given the study's findings that patients with acute lung injury often did not receive lung protective ventilation, greater efforts to implement lung protective ventilation in routine clinical practice should be undertaken to reduce patients' long term mortality.

We thank the patients who participated in the study and the research assistants and coordinators who assisted with data collection and management for the study, including Nardos Belayneh, Rachel Bell, Kim Boucher, Abdulla Damluji, Carinda Feild, Thelma Harrington, Praveen Kondreddi, Robert Lord, Frances Magliacane, Stacey Murray, Kim Nguyen, Susanne Prassl, Arabela Sampaio, Kristin Sepulveda, Shabana Shahid, Faisal Siddiqi, Michelle Silas, and Jennifer Titus. JES is currently assistant professor, Division of Pulmonary, Allergy and Critical Care Medicine, Emory University School of Medicine, Atlanta, Georgia.

Contributors: DMN, PAM-T, JES, CRDH, CS, and PJP contributed to the conception and design of the study. DMN, EC, PAM-T, VDD, JES, $\mathrm{CS}, \mathrm{RGB}$, and PJP analysed and interpreted the data. DMN drafted the article and all other authors critically revised it for important intellectual content. All authors gave final approval of the manuscript version to be published. DMN and EC are responsible for the overall content as guarantors.

Funding: This research was supported by the National Institutes of Health (Acute Lung Injury Specialized Centers of Clinically Oriented Research grant No P050 HL 73994). DNM received support from a clinician-scientist award from the Canadian Institutes of Health Research. JES received support from the National Institutes of Health (NIGMS
K-23 GMO7-1399). All researchers are independent of the funding bodies. The funding bodies had no role in the study design; in the collection, analysis, and interpretation of data; in the writing of the report; and in the decision to submit the manuscript for publication.

Competing interests: All authors have completed the ICMJE uniform disclosure form at www.icmje.org/coi_disclosure.pdf (available on request from the corresponding author) and declare: no support from any organisation for the submitted work; no financial relationships with any organisations that might have an interest in the submitted work in the previous three years; and no other relationships or activities that could appear to have influenced the submitted work.

Ethical approval: This study was approved by the institutional review boards of Johns Hopkins University (No NA_00041630) and all other participating study sites.

Data sharing: No additional data available.

1 Herridge MS, Cheung AM, Tansey CM, Matte-Martyn A, Diaz-Granados N, Al Saidi F, et al. One-year outcomes in survivors of the acute respiratory distress syndrome. $N$ Engl J Med 2003:348:683-93.

2 Cuthbertson BH, Roughton S, Jenkinson D, Maclennan G, Vale L. Quality of life in the five years after intensive care: a cohort study. Crit Care 2010;14:R6.

3 Desai SV, Law TJ, Needham DM. Long-term complications of critical care. Crit Care Med 2011;39:371-9.

4 Rubenfeld GD. Improving clinical trials of long-term outcomes. Crit Care Med 2009;37(Suppl) :S112-6.

5 Petrucci N, lacovelli W. Lung protective ventilation strategy for the acute respiratory distress syndrome. Cochrane Database Syst Rev 2007;(3):CD003844.

6 Fan E, Needham DM, Stewart TE. Ventilatory management of acute lung injury and acute respiratory distress syndrome. JAMA 2005;294:2889-96

7 Putensen C, Theuerkauf N, Zinserling J, Wrigge H, Pelosi P. Meta-analysis: ventilation strategies and outcomes of the acute respiratory distress syndrome and acute lung injury. Ann Intern Med 2009;151:566-76.

8 Brower RG, Matthay MA, Morris A, Schoenfeld D, Thompson BT, Wheeler A. Ventilation with lower tidal volumes as compared with traditional tidal volumes for acute lung injury and the acute respiratory distress syndrome. The Acute Respiratory Distress Syndrome Network. N Engl J Med 2000;342:1301-8.

9 Amato MB, Barbas CS, Medeiros DM, Magaldi RB, Schettino GP, Lorenzi-Filho G, et al. Effect of a protective-ventilation strategy on mortality in the acute respiratory distress syndrome. N Engl J Med 1998;338:347-54.

10 Angus DC, Laterre PF, Helterbrand J, Ely EW, Ball DE, Garg R, et al. The effect of drotrecogin alfa (activated) on long-term survival after severe sepsis. Crit Care Med 2004;32:2199-2206.

11 Slutsky AS, Tremblay LN. Multiple system organ failure. Is mechanical ventilation a contributing factor? Am J Respir Crit Care Med 1998:157(6 Pt 1):1721-5.

12 Bernard GR, Artigas A, Brigham KL, Carlet J, Falke K, Hudson L, et al. The American-European Consensus Conference on ARDS. Definitions, mechanisms, relevant outcomes, and clinical trial coordination. Am J Respir Crit Care Med 1994;149(3 Pt 1):818-24.

13 Fan E, Shahid S, Kondreddi VP, Bienvenu OJ, Mendez-Tellez PA, Pronovost PJ, et al. Informed consent in the critically ill: a two-step approach incorporating delirium screening. Crit Care Med 2008;36:94-9.

14 Social security death index. 2011. http://ssdi.rootsweb.ancestry.com/cgi-bin/ssdi.cgi.

15 Seeley E, McAuley DF, Eisner M, Miletin M, Matthay MA, Kallet RH. Predictors of mortality in acute lung injury during the era of lung protective ventilation. Thorax 2008;63:994-8.

16 Needham DM, Wang W, Desai SV, Mendez-Tellez PA, Dennison CR, Sevransky J, et al. Intensive care unit exposures for long-term outcomes research: development and description of exposures for 150 patients with acute lung injury. J Crit Care 2007;22:275-84 .

17 Charlson ME, Pompei P, Ales KL, MacKenzie CR. A new method of classifying prognostic comorbidity in longitudinal studies: development and validation. $J$ Chronic Dis 1987;40:373-83.

18 Knaus WA, Draper EA, Wagner DP, Zimmerman JE. APACHE II: a severity of disease classification system. Crit Care Med 1985:13:818-29.

19 Seeley EJ, McAuley DF, Eisner M, Miletin M, Zhuo H, Matthay MA, et al. Decreased respiratory system compliance on the sixth day of mechanical ventilation is a predictor of death in patients with established acute lung injury. Respir Res 2011;12:52.

20 Vincent JL, Moreno R, Takala J, Willatts S, De Mendonca A, Bruining H, et al. The SOFA (Sepsis-related Organ Failure Assessment) score to describe organ dysfunction/failure. On behalf of the Working Group on Sepsis-Related Problems of the European Society of Intensive Care Medicine. Intensive Care Med 1996;22:707-10.

21 Ely EW, Truman B, Shintani A, Thomason JW, Wheeler AP, Gordon S, et al. Monitoring sedation status over time in ICU patients: reliability and validity of the Richmond Agitation-Sedation Scale (RASS). JAMA 2003;289:2983-91.

22 Ely EW, Inouye SK, Bernard GR, Gordon S, Francis J, May L, et al. Delirium in mechanically ventilated patients: validity and reliability of the confusion assessment method for the intensive care unit (CAM-ICU). JAMA 2001;286:2703-10.

23 Grambsch $P$, Therneau T. Proportional hazards tests and diagnostics based on weighted residuals. Biometrika 1994;81:515-26.

24 Lin D, Wei L, Ying Z. Checking the Cox model with cumulative sums of Martingale-based residuals. Biometrika 1993;80:557-72.

25 Rubin DB. Multiple imputation after 18+ years. J Am Stat Assoc 1996:91:473-89.

26 Wang W, Scharfstein D, Wang C, Daniels M, Needham D, Brower R. Estimating the causal effect of low tidal volume ventilation on survival in patients with acute lung injury. J R Stat Soc Ser C Appl Stat 2011;60:475-96.

27 Kosuke A, Van Dyk DA. Causal inference with general treatment regimes: generalizing the propensity score. J Am Stat Assoc 2004;99:865-6.

28 Wunsch H, Guerra C, Barnato AE, Angus DC, Li G, Linde-Zwirble WT. Three-year outcomes for Medicare beneficiaries who survive intensive care. JAMA 2010;303:849-56 


\section{What is already known on this topic}

Survivors of critical illness, such as those with acute lung injury, are at increased risk of mortality for years after hospital discharge Volume limited and pressure limited (lung protective) mechanical ventilation decreases short term mortality in patients with acute lung injury, but its association with longer term survival has not been evaluated

\section{What this study adds}

Lung protective mechanical ventilation was associated with a substantial long term survival benefit for patients with acute lung injury Lung protective ventilation is under-utilised in routine clinical practice, necessitating further knowledge translation research to improve uptake of this evidence based therapy

29 Williams TA, Dobb GJ, Finn JC, Knuiman MW, Geelhoed E, Lee KY, et al. Determinants of long-term survival after intensive care. Crit Care Med 2008;36:1523-30.

30 Rubenfeld GD, Caldwell E, Hudson L. Publication of study results does not increase use of lung-protective ventilation in patients with acute lung injury [abstract]. Am J Respir Crit Care Med 2001;163:A295.

31 Weinert CR, Gross CR, Marinelli WA. Impact of randomized trial results on acute lung injury ventilator therapy in teaching hospitals. Am J Respir Crit Care Med 2003;167:1304-9.

32 Young MP, Manning HL, Wilson DL, Mette SA, Riker RR, Leiter JC, et al. Ventilation of patients with acute lung injury and acute respiratory distress syndrome: has new evidence changed clinical practice? Crit Care Med 2004;32:1260-5.

33 Dennison CR, Mendez-Tellez PA, Wang W, Pronovost PJ, Needham DM. Barriers to low tidal volume ventilation in acute respiratory distress syndrome: survey development, validation, and results. Crit Care Med 2007;35:2747-54.

34 Rubenfeld GD, Cooper C, Carter G, Thompson BT, Hudson LD. Barriers to providing lung-protective ventilation to patients with acute lung injury. Crit Care Med 2004;32:1289-93.

35 Umoh NJ, Fan E, Mendez-Tellez PA, Sevransky JE, Dennison CR, Shanholtz C, et al. Patient and intensive care unit organizational factors associated with low tidal volume ventilation in acute lung injury. Crit Care Med 2008;36:1463-8.

36 Needham DM. Patient safety, quality of care, and knowledge translation in the intensive care unit. Respir Care 2010;55:922-8.

37 Pronovost PJ, Murphy DJ, Needham DM. The science of translating research into practice in intensive care. Am J Respir Crit Care Med 2010;182:1463-4.

38 Rubenfeld GD, Caldwell E, Peabody E, Weaver J, Martin DP, Neff M, et al. Incidence and outcomes of acute lung injury. N Engl J Med 2005;353:1685-93.
39 Needham DM, Bronskill SE, Sibbald WJ, Pronovost PJ, Laupacis A Mechanical ventilation in Ontario, 1992-2000: incidence, survival, and hospital bed utilization of noncardiac surgery adult patients. Crit Care Med 2004;32:1504-9.

40 Needham DM, Bronskill SE, Calinawan JR, Sibbald WJ, Pronovost PJ, Laupacis A. Projected incidence of mechanical ventilation in Ontario to 2026: preparing for the aging baby boomers. Crit Care Med 2005;33:574-9.

41 Papazian L, Forel JM, Gacouin A, Penot-Ragon C, Perrin G, Loundou A, et al. Neuromuscular blockers in early acute respiratory distress syndrome. N Engl J Med 2010;363:1107-16.

42 Cooke CR, Kahn JM, Caldwell E, Okamoto VN, Heckbert SR, Hudson LD, et al. Predictors of hospital mortality in a population-based cohort of patients with acute lung injury. Crit Care Med 2008:36:1412-20.

43 Goodman and Gilman's: the pharmacological basis of therapeutics. 11th ed. McGraw-Hill; 2006.

Accepted: 27 February 2012

\section{Cite this as: BMJ 2012;344:e2124}

This is an open-access article distributed under the terms of the Creative Commons Attribution Non-commercial License, which permits use, distribution, and reproduction in any medium, provided the original work is properly cited, the use is non commercial and is otherwise in compliance with the license. See: http://creativecommons.org/licenses/bync/2.0/ and http://creativecommons.org/licenses/by-nc/2.0/legalcode. 


\section{Tables}

Table 1/ Patients' characteristics, by ventilator adherence and mortality status at two years. Values are numbers (percentages) unless stated otherwise

\begin{tabular}{|c|c|c|c|c|c|c|c|}
\hline \multirow[b]{2}{*}{ Characteristics } & \multirow{2}{*}{$\begin{array}{l}\text { All patients } \\
(n=485)\end{array}$} & \multicolumn{2}{|c|}{ Ventilator adherence } & \multirow[b]{2}{*}{$P$ value } & \multicolumn{2}{|c|}{ Mortality status } & \multirow[b]{2}{*}{$P$ value } \\
\hline & & Never $(n=182)$ & Ever $^{*}(n=303)$ & & Alive $(n=174)$ & Dead $(n=311)$ & \\
\hline $\begin{array}{l}\text { Median (interquartile range) age } \\
\text { (years) }\end{array}$ & $53(42-63)$ & $54(45-69)$ & $51(41-60)$ & 0.002 & $46(38-54)$ & $56(47-67)$ & $<0.001$ \\
\hline Males & $274(57)$ & $77(42)$ & $197(65)$ & $<0.001$ & $96(55)$ & $178(57)$ & 0.703 \\
\hline Underweight (body mass index <18.5) & $27(6)$ & $10(6)$ & $17(6)$ & 0.024 & $5(3)$ & $22(7)$ & 0.159 \\
\hline $\begin{array}{l}\text { Normal weight (body mass index } \\
18.5-24.9 \text { ) }\end{array}$ & $150(31)$ & $44(24)$ & $106(35)$ & & $50(29)$ & $100(32)$ & \\
\hline Overweight (body mass index 25-30) & $128(26)$ & $46(25)$ & $82(27)$ & & $51(29)$ & $77(25)$ & \\
\hline Obese (body mass index $>30$ ) & $180(37)$ & $82(45)$ & $98(32)$ & & $68(39)$ & $112(36)$ & \\
\hline $\begin{array}{l}\text { Median (interquartile range) Charlson } \\
\text { comorbidity index }\end{array}$ & $2(1-4)$ & $2(1-4)$ & $2(1-4)$ & 0.433 & $1(0-3)$ & $3(2-5)$ & $<0.001$ \\
\hline $\begin{array}{l}\text { Median (interquartile range) APACHE } \\
\text { II score }\end{array}$ & $27(20-33)$ & $27(20-34)$ & $27(21-33)$ & 0.974 & $22(18-28)$ & $29(22-36)$ & $<0.001$ \\
\hline $\begin{array}{l}\text { Non-pulmonary sepsis as risk factor } \\
\text { for acute lung injury }\end{array}$ & $143(30)$ & $60(33)$ & $83(27)$ & 0.217 & $30(17)$ & $113(36)$ & $<0.001$ \\
\hline $\begin{array}{l}\text { Admission to medical intensive care } \\
\text { unit }\end{array}$ & $411(85)$ & $147(81)$ & $264(87)$ & 0.068 & $137(79)$ & $274(88)$ & 0.008 \\
\hline $\begin{array}{l}\text { Admission to intensive care unit from } \\
\text { emergency department }\end{array}$ & $203(42)$ & $88(48)$ & $115(38)$ & 0.029 & $82(47)$ & $121(39)$ & 0.085 \\
\hline $\begin{array}{l}\text { Median (interquartile range) mean daily } \\
\text { sequential organ failure assessment } \\
\text { score }\end{array}$ & $8(5-12)$ & $8(5-13)$ & $8(5-12)$ & 0.604 & $5(4-7)$ & $10(7-14)$ & $<0.001$ \\
\hline $\begin{array}{l}\text { Median (interquartile range) days of } \\
\text { delirium in intensive care unit }\end{array}$ & $2(0-6)$ & $1(0-4)$ & $3(0-7)$ & $<0.001$ & $3(1-6)$ & $1(0-6)$ & $<0.001$ \\
\hline $\begin{array}{l}\text { Median (interquartile range) days of } \\
\text { deep sedation in intensive care unit }\end{array}$ & $3(1-8)$ & $2(1-5)$ & $4(1-9)$ & $<0.001$ & $3(1-7)$ & $3(1-8)$ & 0.951 \\
\hline Ever received corticosteroids & $325(67)$ & $117(64)$ & $208(69)$ & 0.369 & $96(55)$ & $229(74)$ & $<0.001$ \\
\hline $\begin{array}{l}\text { Median (interquartile range) No of days } \\
\text { of corticosteroid use, if any }\end{array}$ & $6(3-10)$ & $6(3-11)$ & $6(3-10)$ & 0.683 & $6(3-10)$ & $6(3-10)$ & 0.876 \\
\hline $\begin{array}{l}\text { Median (interquartile range) cumulative } \\
\text { dose of prednisone, if any (mg) } \dagger\end{array}$ & $346(156-813)$ & $350(181-863)$ & $338(150-700)$ & 0.262 & $343(134-865)$ & $346(161-735)$ & 0.956 \\
\hline Ever received neuromuscular blocker & $117(24)$ & $31(17)$ & $86(28)$ & 0.004 & $44(25)$ & $73(24)$ & 0.659 \\
\hline $\begin{array}{l}\text { Median (interquartile range) No of days } \\
\text { of neuromuscular blockade, if any }\end{array}$ & $2(1-3)$ & $2(1-3)$ & $1(1-3)$ & 0.583 & $2(1-3)$ & $1(1-3)$ & $>0.99$ \\
\hline $\begin{array}{l}\text { Median (interquartile range) cumulative } \\
\text { dose of vecuronium, if any }(\mathrm{mg})\end{array}$ & $2(1-23)$ & $2(1-79)$ & $1(1-21)$ & 0.229 & $2(1-19)$ & $2(1-26)$ & 0.978 \\
\hline $\begin{array}{l}\text { Median (interquartile range) cumulative } \\
\text { fluid balance in intensive care unit } \\
\text { (litres) }\end{array}$ & $9(3-20)$ & $8(3-17)$ & $10(3-22)$ & 0.162 & $4(0-11)$ & $13(5-24)$ & $<0.001$ \\
\hline $\begin{array}{l}\text { High frequency oscillatory ventilation } \\
\text { (ever) }\end{array}$ & $57(12)$ & $16(9)$ & $41(14)$ & 0.145 & $21(12)$ & $36(12)$ & 0.884 \\
\hline $\begin{array}{l}\text { Airway pressure release ventilation } \\
\text { (ever) }\end{array}$ & $63(13)$ & $17(9)$ & $46(15)$ & 0.070 & $32(18)$ & $31(10)$ & 0.011 \\
\hline $\begin{array}{l}\text { Median (interquartile range) days of } \\
\text { ventilation (eligible setting } \ddagger \text { ) }\end{array}$ & $5(2-9)$ & $3(2-7)$ & $7(4-12)$ & $<0.001$ & $5(3-9)$ & $5(2-10)$ & 0.982 \\
\hline $\begin{array}{l}\text { Median (interquartile range) days of } \\
\text { ventilation (all settings) }\end{array}$ & $9(5-17)$ & $7(4-13)$ & $11(6-21)$ & $<0.001$ & $10(7-17)$ & $8(5-17)$ & 0.031 \\
\hline $\begin{array}{l}\text { Median (interquartile range) length of } \\
\text { stay in intensive care unit (days) }\end{array}$ & $13(8-22)$ & $11(6-18)$ & $15(8-25)$ & $<0.001$ & $15(10-22)$ & $13(6-22)$ & 0.004 \\
\hline $\begin{array}{l}\text { Median (interquartile range) length of } \\
\text { stay in hospital (days) }\end{array}$ & $21(13-36)$ & $17(9-30)$ & $24(15-39)$ & $<0.001$ & $24(17-36)$ & $18(10-34)$ & $<0.001$ \\
\hline
\end{tabular}

APACHE II=acute physiology and chronic health evaluation II. 


\section{Table 1 (continued)}

\begin{tabular}{|c|c|c|c|c|c|c|c|}
\hline \multirow[b]{2}{*}{ Characteristics } & \multirow{2}{*}{$\begin{array}{l}\text { All patients } \\
(n=485)\end{array}$} & \multicolumn{2}{|c|}{ Ventilator adherence } & & \multicolumn{2}{|c|}{ Mortality status } & \\
\hline & & Never $(n=182)$ & Ever* $(n=303)$ & $P$ value & Alive $(n=174)$ & Dead $(n=311)$ & $P$ value \\
\hline
\end{tabular}

*Defined using average of five imputed plateau pressures for patients with missing data.

†Corticosteroid dose presented as prednisone-equivalent dose; conversions done using standard methods. ${ }^{43}$

$\ddagger$ Defined as eligible for lung protective ventilation if mechanical ventilation was delivered through an endotracheal or tracheostomy tube with fraction of inspired oxygen $\geq 0.50$ or positive end expiratory pressure $>5 \mathrm{~cm}$ of water. Ventilator modes for which tidal volume is not routinely measured (high frequency oscillation or airway pressure release) were considered not eligible for analysis of lung protective ventilation. 
Table 2| Mechanical ventilation variables by adherence to lung protection and mortality status at two years. ${ }^{*}$ Values are median (interquartile range) unless stated otherwise

\begin{tabular}{|c|c|c|c|c|c|c|c|}
\hline \multirow[b]{2}{*}{ Ventilation variables } & \multicolumn{3}{|c|}{ Ventilator settings $\dagger$} & \multirow[b]{2}{*}{$P$ value $\neq$} & \multicolumn{2}{|c|}{ Mortality status } & \multirow[b]{2}{*}{ P value $\ddagger$} \\
\hline & $\begin{array}{l}\text { All eligible } \\
(n=6240)\end{array}$ & $\begin{array}{c}\text { Non-adherent } \\
(n=3692)\end{array}$ & Adherent ( $n=2548)$ & & Alive $(n=2083)$ & Dead $(n=4157)$ & \\
\hline $\begin{array}{l}\text { Positive end expiratory } \\
\text { pressure }\left(\mathrm{cm} \mathrm{H}_{2} \mathrm{O}\right)\end{array}$ & $10(8-10)$ & $10(5-10)$ & $10(8-10)$ & 0.070 & $10(8-10)$ & $10(7-10)$ & 0.971 \\
\hline $\mathrm{PaO}_{2}: \mathrm{FiO}_{2}$ & $172(114-215)$ & $180(114-234)$ & $165(113-199)$ & $<0.001$ & $188(128-234)$ & $163(107-208)$ & $<0.001$ \\
\hline $\begin{array}{l}\text { No (\%) with arterial } \mathrm{pH} \\
<7.25 \S\end{array}$ & $634(10)$ & $379(10)$ & $255(10)$ & 0.216 & $126(6)$ & $508(12)$ & $<0.001$ \\
\hline $\begin{array}{l}\text { Static compliance of } \\
\text { respiratory system } \\
\left(\mathrm{mL} / \mathrm{cm} \mathrm{H}_{2} \mathrm{O}\right)\end{array}$ & $31(23-42)$ & $32(23-44)$ & $30(24-39)$ & $<0.001$ & $31(23-42)$ & $31(24-42)$ & 0.177 \\
\hline $\begin{array}{l}\text { Plateau pressure } \mathbb{( \mathrm { cm }} \\
\left.\mathrm{H}_{2} \mathrm{O}\right)\end{array}$ & $23(20-27)$ & $24(20-28)$ & $23(20-26)$ & $<0.001$ & $23(20-27)$ & $23(20-27)$ & 0.943 \\
\hline $\begin{array}{l}\text { Respiratory rate } \\
\text { (breaths } / \mathrm{min} \text { ) }\end{array}$ & $27(20-35)$ & $24(19-32)$ & $30(24-35)$ & $<0.001$ & $26(20-35)$ & $28(20-35)$ & 0.018 \\
\hline $\begin{array}{l}\text { Tidal volume (mL/kg } \\
\text { predicted body weight) }\end{array}$ & $6.6(5.9-7.8)$ & $7.5(6.8-8.6)$ & $5.9(5.6-6.1)$ & $<0.001$ & $6.6(6.0-7.9)$ & $6.6(5.8-7.8)$ & 0.014 \\
\hline
\end{tabular}

$\mathrm{PaO}_{2}=$ partial pressure of arterial oxygen; $\mathrm{FiO}_{2}=$ fraction of inspired oxygen .

*All variables are for eligible mechanical ventilator settings.

†Defined as eligible for lung protective ventilation if mechanical ventilation was delivered through an endotracheal or tracheostomy tube with $\mathrm{FiO}{ }_{2} \geq 0.50$ or positive end expiratory pressure $>5 \mathrm{~cm}$ of water. Ventilator modes for which tidal volume is not routinely measured (high frequency oscillation or airway pressure release) were considered not eligible for analysis of lung protective ventilation.

$\ddagger \mathrm{P}$ values are adjusted for within patient correlation using robust variance estimate.

§From arterial blood gas measurements abstracted from medical records twice daily, when available.

IPlateau pressures represent average value over five imputed datasets for patients with missing values. 


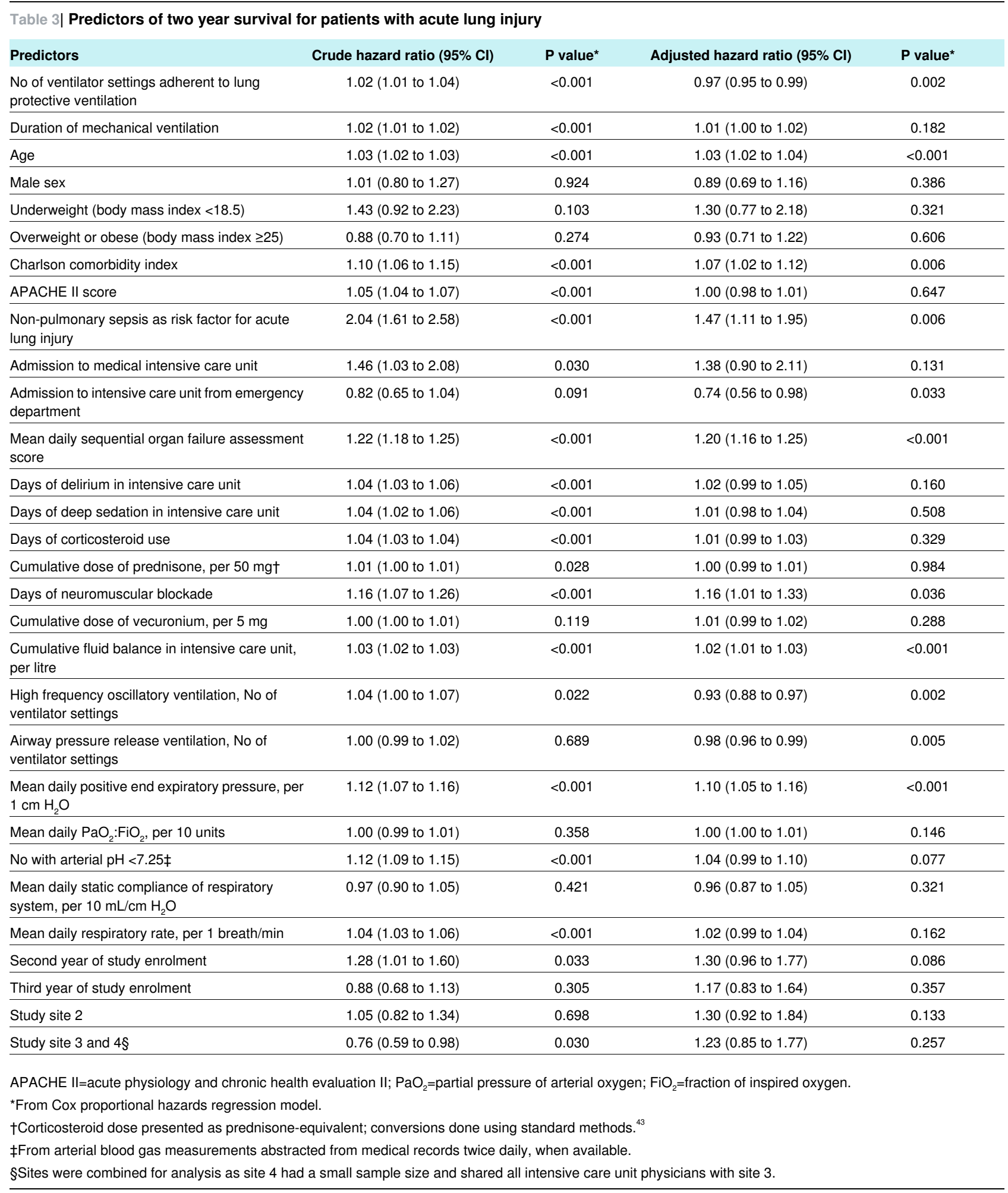




\section{Figures}

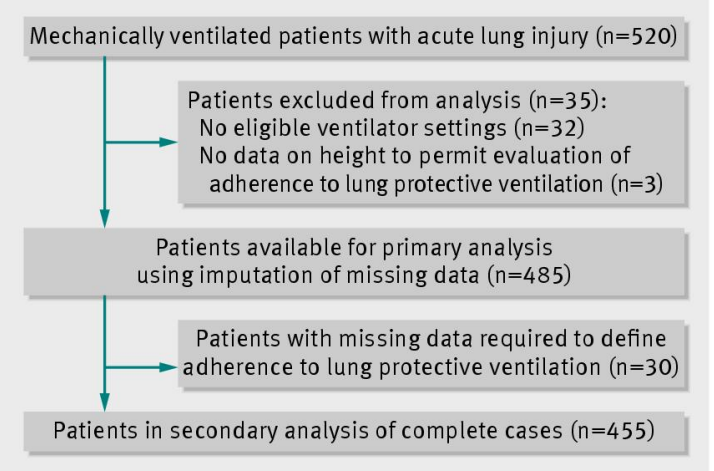

Fig 1 Flow of patients through study

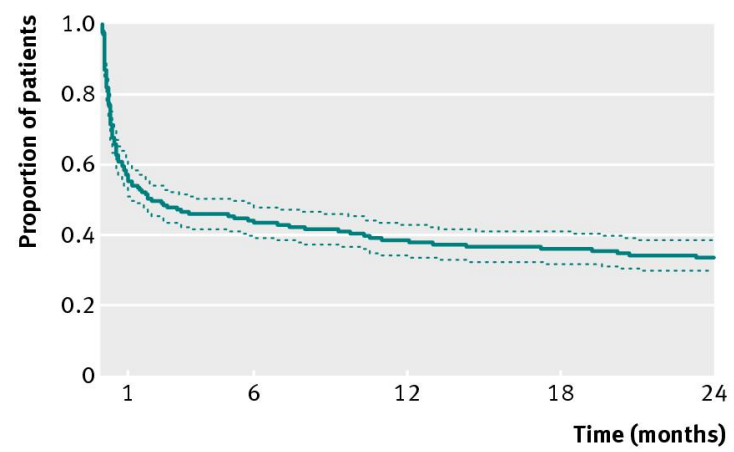

Fig 2 Unadjusted Kaplan-Meier survival curve, with 95\% confidence limits, for 485 patients with acute lung injury in primary analysis

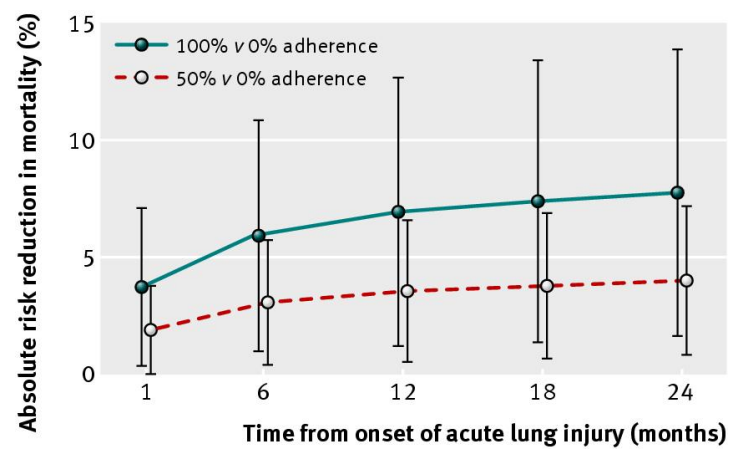

Fig 3 Predicted absolute risk reduction in mortality by adherence to lung protective ventilation. Estimates based on Cox proportional hazards regression model with time varying covariates used to predict survival estimates for a prototypical patient with eight eligible mechanical ventilator settings with $0 \%$ versus $50 \%$ or $0 \%$ versus $100 \%$ adherence to lung protective ventilation. The prototypical patient was presumed to survive for at least four days of eligible ventilation and had median values for all continuous covariates and mode values for binary covariates. Confidence intervals were generated using 500 bootstrap samples 


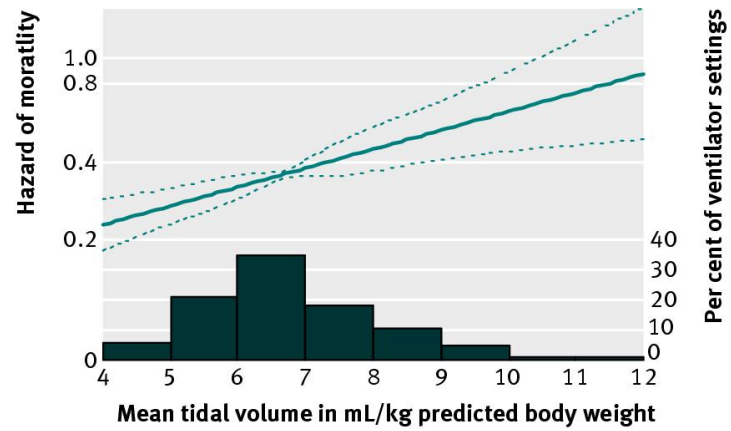

Fig 4 Predicted change in hazard of mortality for increasing mean tidal volume, based on multivariable Cox model, across 485 patients with acute lung injury. A more flexible non-linear Cox model for mean tidal volume (cubic spline with three degrees of freedom) did not yield significant improvement in model fit compared with linear model $(\mathrm{P}=0.182$ for non-linear terms in cubic spline model) 